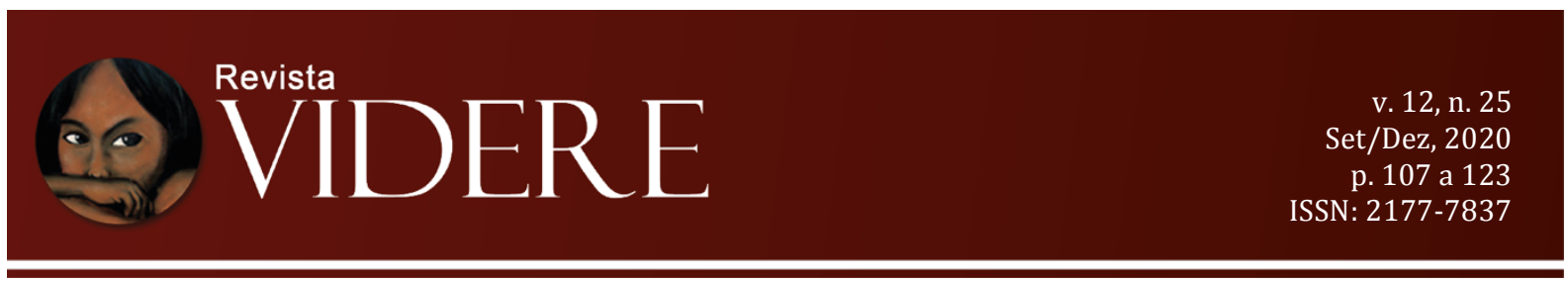

\title{
CONTRARREFORMAS TRABALHISTAS E (MAIS)VALORIZAÇÃO DA NEGOCIAÇÃO COLETIVA NO CONTEXTO DA CRISE SANITÁRIA
}

\author{
LABOR LAW CONTRARREFORMS AND (SURPLUS)VALUATION OF COLLECTIVE \\ BARGAINING IN THE CONTEXT OF SANITARY CRISIS
}

\author{
CONTRARREFORMAS LABORALES Y (PLUS) VALORACIÓN DE LA \\ NEGOCIACIÓN COLECTIVA EN EL CONTEXTO DE LA CRISIS SANITARIA
}

\begin{abstract}
Gustavo Seferian
Doutor em Direito - Universidade de São Paulo - USP Professor da Universidade Federal de Minas Gerais - UFMG seferian@ufmg.br

OrcidID: : http://orcid.com/0000-0002-5587-6734
\end{abstract}

\begin{abstract}
Resumo: O artigo aborda as alterações trazidas na CLT no que se refere ao permissivo à negociação coletiva para flexibilizar direitos trabalhistas legalmente consagrados. Desde o materialismo histórico e dialético, e discutindo aspectos dogmáticos, históricos e sociais da juridicidade, o estudo busca demonstrar que esta alteração legislativa, em que pese revestida de traços ideológicos que sinalizem em sentido diverso, é um reflexo da ofensiva burguesa ante os direitos trabalhistas, evidenciando que (i) a "valorização" da composição coletiva nada traz de prestígio à concertação social como meio eficaz de adequação das relações trabalhistas; (ii) que sua principal funcionalidade é a indução ao aprofundamento da lógica de exploração da força de trabalho, daí poder ser lida como uma mais-valorização da negociação coletiva; (iii) servindo de fissura relevante a proporcionar aberturas à radicalização da autonomia individual da vontade, a exemplo do julgamento pelo STF da ADI 6.363, em abril de 2020, no contexto da crise sanitária resultante da pandemia da COVID-19.
\end{abstract}

Palavras-chave: Negociação coletiva. Precarização. Mais-valorização. Autonomia individual da vontade. COVID-19.

Abstract: The article deals with the changes brought in the brazilian labor legislation granting collective bargaining permissiveness to make legal labor rights more flexible. Taking the historical and dialectical materialism as method, and discussing dogmatic, historical and social aspects of legality, the study seeks to demonstrate that this legislative change, despite having ideological traits that signal in a different sense, is a reflection of the bourgeois offensive against labor rights, evidencing that (i) the "valorization" of the collective 
composition does not bring prestige to social concertation as an effective mean for adjusting labor relations; (ii) that its main functionality is the induction to deepen the workforce exploitation, hence it can be read as an surplus-valuation of collective bargaining; (iii) serving as a relevant fissure to provide openings to the radicalization of the individual autonomy of the will, such as the judgment by the Brazilian Supreme Court of the ADI 6.363, in April 2020, in the context of the sanitary crisis resulting from the pandemic of COVID-19.

Keywords: Collective bargaining. Precariousness. Surplus-valuation. individual autonomy of the will. COVID-19.

Resumen: El artículo aborda los cambios introducidos en la legislación laboral brasileña - la CLT -, en cuanto a la permisividad a la negociación colectiva para flexibilizar los derechos laborales legales. Desde el materialismo histórico y dialéctico, y discutiendo aspectos dogmáticos, históricos y sociales de la legalidad, el estudio busca demostrar que este cambio legislativo, a pesar de los rasgos ideológicos que señalan en otro sentido, es un reflejo de la ofensiva burguesa contra los derechos laborales, mostrando que (i) la "valorización" de la negociación colectiva no aporta nada de prestigio a la consulta social como medio efectivo de ajuste de las relaciones laborales; (ii) que su principal funcionalidad es la inducción para profundizar en la lógica de explotación de la fuerza de trabajo, por lo que puede leerse como una sobrevaloración de la negociación colectiva; (iii) sirviendo como una fisura relevante para abrir las puertas a la radicalización de la autonomía individual de la voluntad, como la sentencia del STI de ADI 6.363, en abril de 2020, en el contexto de la crisis de salud derivada de la pandemia de COVID-19.

Palabras clave: Negociación colectiva. Precariedad. Sobrevaloración. Autonomía individual de la voluntad. COVID-19

\section{Introdução}

A contrarreforma trabalhista instituída pela Lei n. 13.467/2017 não gerou poucas polêmicas. Seja pelo rechaço popular, pelo açodado processo de tramitação e aprovação, ou pelos efeitos que pretendeu projetar na realidade social e econômica brasileira - e que de fato não podem ser alcançados, ao menos por seus próprios meios -, segue desde o momento inicial de sua propositura no centro das atenções de trabalhadoras, trabalhadores e empregadores brasileiros.

Dentre as mais de duas centenas de alterações advindas da contrarreforma (SEVERO, SOUTO MAIOR, 2017), destacamos pelos agudos impactos potenciais no Direito do Trabalho - em parte já experimentados nestes mais de dois anos que se encontra em vigor - a alteração dada aos efeitos da negociação coletiva, ou aquilo que se convencionou chamar de prevalência do negociado sobre o legislado.

Muito embora a tônica posta na conformação dos arts. 611-A e 611-B, da CLT, sinalize acolhida do discurso da "valorização" da negociação coletiva, colocando na ação dos 
agentes coletivos as melhores soluções para o arranjo das relações laborais, sobretudo na busca pela preservação de postos de trabalho, o que se verifica em verdade é que tal instituto tem serventia exclusiva de fragilização da proteção social posta pelo Direito do Trabalho, proporcionando a maximização da exploração pelo assalariamento. A explicitação desta intenção colocada em marcha nos processos de contrarreformas se denota, sintomaticamente, no período da pandemia da COVID-19: a autonomia coletiva da vontade é solenemente descartada em prol de um instrumento ainda mais eficaz nesta busca: a negociação individual.

Com o presente artigo, pretendemos assim lidar com o processo que desembocou em tal alteração no texto Consolidado, bem como com os desdobramentos do trato da negociação coletiva e individual para fins de retração de direitos no bojo da crise sanitária , sobretudo tendo em conta a Medida Provisória n. 936, de $1^{\circ}$ de abril de 2020, e o julgamento pelo Supremo Tribunal Federal da Ação Direta de Inconstitucionalidade 6.363, ainda no mês de abril de 2020.

Amparando-se no método materialista dialético e histórico, e desenvolvendo formulação de caráter teórico crítico à dogmática do Direito Coletivo do Trabalho, buscaremos (i) expor o movimento histórico - ou seja, de luta classista - que serviu à alteração da CLT pela Lei 13.467/2017, proporcionando a prevalência da negociação coletiva sobre a legislação; (ii) revelar as aberturas estruturais proporcionadas pela mudança, mostrando-as como relevante mecanismo de flexibilização de Direitos Trabalhistas, avesso às premissas constitucionais pátrias; (iii) discutir o conteúdo da ideia da "valorização" da negociação coletiva, que nada se associa ao seu prestígio, mas sim à lógica de exploração perpetrada pelo capital, que se intensifica com os novos efeitos da negociação coletiva, viabilizando a ampliação do mais-valor extraído pelos tomadores da força de trabalho; (iv) demonstrar como, sintomaticamente, a adoção da Medida Provisória n. 936/2020 e o julgamento da ADI 6.363 demonstrar ser a legalização do negociado sobre o legislado uma fissura apta a ensejar flexibilizações ainda mais agudas, a exemplo da ampliação da autonomia individual da vontade em matéria trabalhista.

\section{A legalização da prevalência da negociação coletiva sobre o legislado e sua contrariedade ao texto constitucional}

Incorporada em nosso ordenamento jurídico de forma mais sólida pela inclusão dos arts. 611-A e 611-B, no texto da CLT, bem como pela alteração no texto do art. 620, do 
mesmo diploma normativo, a prevalência do negociado coletivamente sobre o legislado merece ser discutida previamente em alguns de seus aspectos dogmáticos.

O texto do artigo 611-A, que mal tendo entrado em vigor a Lei n. 13.467/2017 passou por alterações decorrentes da Medida Provisória n. 808/2017 ${ }^{1}$, voltou a vigorar com sua redação original em 23 de abril de 2018, dispondo que "a convenção coletiva e o acordo coletivo de trabalho têm prevalência sobre a lei”, exceptuado no que refere aos títulos trazidos no também recente art. 611-B, Consolidado - que, em larga medida, elenca o conjunto de Direitos Trabalhistas previstos no art. $7^{\circ}$, da Constituição da República.

Já o art. 620, da CLT, que desde a redação dada pelo Decreto n.229/1967 estipulava que "as condições estabelecidas em Convenção, quando mais favoráveis [ao trabalhador e à trabalhadora, G.S.], prevalecerão sobre as estipuladas em Acôrdo", passou a sinalizar que "as condições estabelecidas em acordo coletivo de trabalho sempre prevalecerão sobre as estipuladas em convenção coletiva de trabalho".

Referidas alterações, que subvertem as clássicas regras de validade normativa trabalhistas e que de curto a médio prazo expressam tendência precarizadora dos arranjos da contratação da força de trabalho no país - em parte já confirmada (BATISTA, SEFERIAN, 2020) -, foram acompanhadas por um conjunto de outras mudanças na CLT para lhes dar corpo e viabilizar sua aplicação prática. Exemplo maior foi a decorrente da extinção da contribuição sindical e o estabelecimento de nova mecânica arrecadatória aos sindicatos, alterando os arts.578 e 579, da CLT. Referidas mudanças proporcionaram duro impacto no financiamento e manutenção das atividades de muitos sindicatos, fato que teve por consequência imediata a míngua das condições negociais de categorias mais frágeis ou com pouco histórico de articulação sindical, e a concentração de atos negociais trazendo favorecimento aos trabalhadores e trabalhadoras em categorias com maior tradição e índices mais altos de sindicalização (BATISTA, SEFERIAN, 2020).

Todavia, é certo que tais mudanças normativas não surgiram no bojo da contrarreforma instituída pela Lei n. 13.467/2017 como um raio em céu azul. Consolidam-se pautadas em um esforço histórico das classes proprietárias - mas também, contraditoriamente, de setores das classes trabalhadoras amparados em perspectivas conciliatórias de classe - em minar alguns dos sustentáculos mais rijos da conformação clássica do Direito do Trabalho. E por históricos, vale frisar, não atrelamos apenas à compreensão de que derivam da afirmação de uma classe sobre outra (MARX, ENGELS, 2010, p.40), mas também em um sentido 
menos rigoroso, dada a ancestralidade da iniciativa: já há muito tais investidas vinham sendo encampadas, assumindo vulto sobretudo nos momentos de maior fulgor do ascenso neoliberal, sendo que no célere processo de aprovação da Lei n. 13.467/2017 viram-se fortalecidas pelos discursos defensores da "modernização" da legislação do trabalho e "valorização" da negociação coletiva.

É de se ter em conta que a sistemática colocada em marcha para o trato da negociação coletiva no Brasil não admitia fossem os ajustes firmados entre representantes obreiros e patronais hábeis a subtrair direitos trabalhistas, sejam os estabelecidos em lei, sejam os já aderentes ao contrato individual de trabalho - a exemplo do conteúdo da Súmula n. 277, do Tribunal Superior do Trabalho, que vertebrara enquanto instituto a ultratividade das normas coletivamente compostas, hoje afrontado pelo art. 614, parágrafo terceiro, da CLT. Indiferentemente do instrumento de composição coletiva, a lógica prevalente apenas permitia a incorporação de novos direitos aos trabalhadores e trabalhadoras.

Não é de se estranhar, pois, que o texto consagrado em nossa Constituição - mais especificamente no art. $7^{\circ}$, caput, combinado com seu inciso XXVI -, fruto, entre outros tantos processos sociais, do ascenso de classe experimentado desde 1978 no país, sinalize que pela negociação coletiva só se admita melhorias das condições econômicas e sociais das pessoas que trabalham:

Art. $7^{\circ}$ São direitos dos trabalhadores urbanos e rurais, além de outros que visem à melhoria de sua condição social:

$(\ldots)$

XXVI - reconhecimento das convenções e acordos coletivos de trabalho;

Da mesma sorte, dimana a compreensão dada desde 1967 ao art. 620, da CLT, que, como exposto, apontava a prevalência das convenções coletivas frente aos acordos no caso das primeiras trazerem normas mais favoráveis às trabalhadoras e trabalhadores, em que pese a especialidade dos acordos firmados diretamente com os empregadores individuais.

Em suma, a hierarquização normativa imperante quanto a negociação coletiva sempre seguiu a tônica comum impressa às normas trabalhistas: avessa aos marcos exclusivos de temporalidade, especificidade ou hierarquia, que dimanam das regras gerais de aplicação do Direito previstas no Decreto-Lei n. 4.657/1942, o Direito do Trabalho estruturou suas próprias regras de hierarquização e validade normativas, calcadas, sobretudo, na perspectiva da mais ampla proteção aos trabalhadores e trabalhadoras.

Teoricamente, esta mecânica se manifesta de melhor modo na clássica lição de Américo Plá Rodriguez (2000). Esta anuncia que o mais importante dos princípios juslaborais 
- o Princípio da Proteção - se alicerça no tripé do in dubio pro operario, da norma mais favorável, da condição mais benéfica. E é justamente quanto ao segundo referencial estruturante do princípio que as inflexões que ora voltamos nosso olhar crítico atentam, alterando a compreensão geral e tradicional no âmbito juslaboral no sentido de que "não se aplicará a norma correspondente dentro de uma ordem hierárquica predeterminada, mas se aplicará, em cada caso, a norma mais favorável ao trabalhador (PLÁ RODRIGUEZ, 2000, p. $52)$.

Tal sistemática protetiva - que fora coroada pelo supracitado art. $7^{\circ}$, da Constituição da República, com a afirmação do princípio da vedação do retrocesso social -, combinado ao citado inciso XXVI, denota não só o estímulo e o reconhecimento dos instrumentos de negociação coletiva, como também a circunscrição de seus efeitos, sinalizando a impossibilidade sistêmica de admissão, ao menos à luz constitucional, de alterações coletivamente compostas que resultem em prejuízo aos trabalhadores e trabalhadoras.

Mesmo diante desse repertório normativo e principiológico, intentou a contrarreforma trabalhista operacionalizada pela Lei n. 13.467/2017 colocar profundas alterações na sistemática das negociações coletivas vigente há décadas no país, daí resultar tamanho o impacto potencial na regulamentação da contratação da força de trabalho.

É sabido que a estrutura sindical pátria foi juridicamente assentada com o intuito de fomentar a lógica de pacificação social por meio da conciliação de classe. Nada de novo sob o sol, aliás. Apenas a expressão de uma tendência forte manifesta no seio das sociedades capitalistas centrais e periféricas no sentido de interditar, pelo controle da luta organizada da população assalariada e estímulo a práticas negociais, as possibilidades de convulsão social.

Desde as primeiras leis brasileiras acerca da matéria sindical, ainda no início do séc. XX, percebe-se a intenção do poder estabelecido em regulamentar o exercício das entidades de classe, sinalizando suas finalidades sociais - a exemplo do Decreto n. 1.673, de 5 de janeiro de 1907, que em seu art. $8^{\circ}$ menciona estar no escopo da ação dos sindicatos revestidos de legalidade "constituírem com o espírito de harmonia entre patrões e operários, (...) conselhos permanentes de conciliação e arbitragem, destinados a dirimir as divergencias e contestações entre o capital e o trabalho" - e limites de horizonte de suas práticas, em explícito movimento de captura e legalização da classe (EDELMAN, 2016). A tônica segue vigorosa nos períodos históricos seguintes. Com o transcorrer das recomposições marcadas pelo regime de gestão do capital em modelo corporativo, forjam-se os traços estruturantes da organização sindical brasileira - dita por Boito Júnior (1991) como sendo a de um 
sindicalismo de Estado -, que perdura com poucas variações até os dias de hoje (sendo a mais marcante advinda também da Lei n. 13.467/2017, com o fim da contribuição sindical), servindo de permanente mecanismo de constrição à auto-organização combativa das trabalhadoras e trabalhadores.

Ainda que tais intentos neutralizadores dos potenciais políticos despontem como características centrais da organização sindical pátria, também de forma indelével se notam os registros do enfrentamento das trabalhadoras e trabalhadores ao processo de captura institucional da ação sindical, fato que aflora inclusive da leitura dos textos jurídicos. Foi essa tradição conformativa de lutas obreiras, em caráter de resistência ou ofensiva, que consubstanciou as balizas negociais coletivas a partir do respeito aos princípios juslaborais forjados, da mesma sorte, nesse processo histórico -, sinalizando que só poderiam os atos negociais interclasses ensejar a ampliação de direitos daquelas e daqueles que vivem da venda da força de trabalho, mantendo os direitos consagrados na CLT como referencial mínimo e intransponível destas pactuações.

Não por outra razão o traço normativo de maior pujança neste sentido - o já mencionado texto do art. $7^{\circ}$, da Constituição Federal - tenha sido a resultante de um processo de ascenso popular de trabalhadores e trabalhadoras, iniciado no fim dos anos 1970 com a as greves nas regiões do ABC paulista e da exploração da borracha no Acre, irradiando-se por todo o país e impulsionando outros movimentos sociais, que não de natureza sindical.

Compreendendo que a natureza dos efeitos das cláusulas coletivamente compostas é fruto de um processo político - decorrendo sobretudo do poder afirmativo das classes trabalhadoras em luta, e que mesmo administradas juridicamente pela regulamentação sindical, fazem valer seus genuínos interesses na lógica negocial -, não podemos perder de mente que as proposições advindas da Lei n. 13.467/2017 são também fruto do processo de luta classista, e demonstrar a ofensiva burguesa contra os direitos historicamente conquistados pelas classes trabalhadoras (e contra as próprias classes trabalhadoras!) pela nada sutil alteração nos limites da autonomia da vontade coletiva em seara laboral.

É de se ressaltar que desde 11 de novembro de 2017, sob a discursividade de estímulo à liberdade e à negociação sindicais, percebe-se que os interesses patronais alçam-se a um novo patamar de possibilidades, isso diante da legalização da prevalência absoluta do coletivamente negociado frente ao legislado.

A nova lógica se afirma baseada nas perspectivas de que a negociação coletiva, ao ser fomentada, deve atender aos anseios mais amplos de sustentabilidade empresarial e viabilização da atividade econômica, ao arrepio da lógica de proteção que sempre se colocou 
enquanto tônica do Direito do Trabalho e marca da negociação coletiva. Tudo isso sob o lustro de que, em verdade, apenas se estaria estimulando as práticas negociais como forma de solução de conflitos coletivos de trabalho.

Convém mencionar que a expressão ideológica que defende os intentos flexibilizadores pela negociação coletiva projetaram a tais práticas de subtração negociada de direitos uma carga "protetiva" às trabalhadoras e trabalhadores, sobretudo quando estamos diante do fato de que a minoração das salvaguardas de renda, os limites de jornada e os meios de não exposição a riscos à saúde, segurança e higiene no labor resultariam na manutenção de postos de trabalho e, logo, a atenção aos anseios de renda mínima e reprodução pura e simples da vida social, supostamente tão reclamados pelos trabalhadores e trabalhadoras.

Esta ginástica teórica, porém, não denota um exercício protetivo. Na verdade, se caracteriza como afronta à afirmação do poderio dos trabalhadores e trabalhadoras nesse certame tão arisco às vencidas da história que é a juridicidade. Redirecionar a lógica protetiva juslaboral à proteção da empregabilidade não se reflete, pois, uma alternativa viável à atenção dos interesses de quem trabalha.

\section{Normatização acessória à prevalência precarizadora da negociação coletiva}

Combinado a esses novos referenciais normativos que pretendem ampliar os efeitos da negociação coletiva a fim de violentar os direitos historicamente conquistados pelas classes trabalhadoras, é de se perceber toda uma série de outras alterações que retroalimentam a afirmação dos interesses patronais no bojo da negociação coletiva.

Nota-se da Lei n. 13.467/2017 um conjunto de mudanças que se voltaram à redação do art. $8^{\circ}$, da CLT, e que por duas mãos pretende atingir o trato da negociação coletiva no Brasil. De um lado, houve a exclusão do texto Consolidado a menção ao império dos "princípios fundamentais" do Direito do Trabalho na interpretação e aplicação juslaboral, sobretudo no trato de normas estranhas às da CLT. De outro, alça-se o "princípio da intervenção mínima na autonomia da vontade coletiva" como guia na abordagem dos negócios jurídicos entre sindicatos.

Com a primeira alteração, o que se percebe é uma tentativa de evitar que a tradição historicamente forjada de aplicação principiológica ao Direito do Trabalho seja perenizada, criando óbices sobretudo à atuação do Judiciário na aplicação de normas estranhas ao texto da CLT e que proporcionem a ampliação protetiva das trabalhadoras e trabalhadores. Como vemos, a vedação aos efeitos deletérios a quem trabalha por meio da 
negociação coletiva mantém lastro forte nos "princípios fundamentais" cuja aplicação se intenta interditar, motivo que seria já bastante e suficiente para denotar a intencionalidade patronal com a referida alteração normativa.

Varridos os "princípios fundamentais" juslaborais do texto da lei, subsiste - ou se coloca como inovação textual-normativa - a menção ao "princípio da intervenção mínima na autonomia da vontade coletiva". Referido "princípio" - que brota no texto Consolidado sem qualquer maturação teórica, jurisprudencial ou histórica - permanece enquanto referência indispensável à salvaguarda dos interesses burgueses no trato trabalhista por sinalizar a impossibilidade de questionamento, por qualquer esfera ou poder, aos termos negociais coletivos que venham a ser firmados.

Uma vez mais, é o Poder Judiciário Trabalhista o principal destinatário da norma: em sendo possível e esperado o agir incisivo dos magistrados e magistradas frente a acordos e convenções coletivas que infrinjam Direitos Trabalhistas constitucional e legalmente garantidos, uma tomada próxima ao absoluto da autonomia da vontade coletiva levaria à interdição de mecanismos de controle protetivos encampados pelo supracitado Poder.

Ocorre, porém, que já se sinaliza que essa "intervenção mínima" comporta modulações. Primeiro, em razão de se aplicar apenas à negociação coletiva, e não a toda estrutura organizativa sindical. Em segundo lugar, a aplicação pelo Judiciário do dito princípio, mesmo na negociação coletiva, vige não a partir de algum grau de intangível objetividade, mas conforme a conveniência de interesses de classe. E no momento, não são os interesses das classes trabalhadoras que se mostram em ofensiva ou mesmo no compor hegemônico da Justiça do Trabalho, mas sim, explicitamente, o das classes proprietárias que assumem a dianteira.

Podemos entender que, em abstrato e atrelado a outros fatores sociais, referido princípio de não-intervenção modulada, ou seja, de intervenção mínima, seria de todo salutar. O que ocorre, porém, é que o atual arranjo das organizações sindicais pátrias, aliado com a perspectiva de crescente fragilização dos sindicatos de Estado burocratizados e dependentes de contribuições compulsórias, tende a fomentar perspectivas de crescente viabilização de manutenção dos aparelhos burocráticos por vias negociais, seja por caminhos lícitos - como o estabelecimento de contribuições nas negociações coletivas - ou ilícitos - com a "venda", pelas diretorias pelegas, de direitos historicamente conquistados pelas categorias que avocam representar, ou ao menos formalmente representam.

\section{Os passos que precedem a legalização da precarização negociada}


A prevalência do negociado coletivamente sobre o legislado guarda uma história recente bastante mais dinâmica do que os curtos meses de tramitação do Projeto de Lei n. $6.787 / 2016$.

É fundamental ter em conta que a referida alteração legislativa, ao revés da maior parte dos ataques advindos da Lei n. 13.467/2017, foi objeto de discussões e defesas por diversos segmentos da sociedade, inclusive, para o assombro de desavisadas e desavisados, de setores tidos por combativos do movimento sindical. É o exemplo do encampar, por parte do Sindicato dos Metalúrgicos do $\mathrm{ABC}$, do outrora chamado Acordo Coletivo Especial, que em sua essência guarda as mesmas características desse traço da contrarreforma (MEIRELLES, 2012).

A entidade de classe precursora no ascenso social que ensejou o Novo Sindicalismo serviu também de ponta de lança à experimentação de uma série de medidas inovadoras na prática sindical, muitas decorrentes do exercício criativo de seu forte corpo jurídico. Exemplo disso foi o estímulo às trabalhadoras e trabalhadores de sua base representativa para que constituíssem cooperativas com vistas a autogerir empresas falidas no curso da década de 1990 (MAUAD, 1999). A defesa do Acordo Coletivo Especial, porém, é um tanto mais perversa aos direitos laborais que o exercício cooperativo, já que em verdade revela uma percepção distorcida da realidade: pautada na apreensão da situação particular de um sindicato forte e historicamente consolidado, capaz de se colocar em patamar de maior proximidade - ainda que jamais em pé de igualdade - para negociar com o setor patronal, pretendia pretendia ampliar para a completude das entidades da classe trabalhadora uma mesma abertura de possibilidades, ainda que estar não gozem da mesma rijeza e capacidade de barganha, levando-as a invariavelmente ajustar pactos que possam preterir direitos historicamente conquistados.

Todavia, as inflexões conjunturais - impactadas sobretudo pela crise global da finança neoliberal na realidade brasileira e o golpe de Estado ocorrido em 2016 - levaram o Sindicato em menção a deixar de lado referida pauta, que então passava a também figurar, sob outra alcunha e entre outras tantas propostas, o programa político golpista de título Uma Ponte para o Futuro ${ }^{2}$.

2 PMDB. "Uma ponte para o futuro", disponível em: <https://www.fundacaoulysses.org.br/wpcontent/uploads/2016/11/UMA-PONTE-PARA-O-FUTURO.pdf>, acessado em 24.04.2018. 
Ainda que já aventada em momentos anteriores pelos governos de cariz socialliberal $^{3}$, tendo dado passos modulados nesse sentido com a instituição do Plano de Proteção ao Emprego, foi apenas após o golpe que foram encaminhados concretamente os esforços para implementação dessa alteração legal. E afora as articulações no campo da pequena política, indispensáveis para a aprovação da Lei n. 13.467/2017, foram inúmeros os esforços discursivos e ideológicos na busca de legitimação de tal alteração legislativa.

\section{A "mais-valorização" da negociação coletiva}

Assume destaque o argumento, no fluxo de ideias que se voltam à "modernização" das relações de trabalho (SEFERIAN, 2017b, p.57, 2019, p.18), da "valorização da negociação coletiva". Trabalhada há muitos anos pelo Ministro e articulador de interesses patronais no Tribunal Superior do Trabalho Ives Gandra Martins Filho (2006), esta "valorização da negociação coletiva" em nada se compatibiliza com as premissas sindicais classicamente assentadas nas práticas social e jurídica brasileiras, sobretudo ante as demandas de trabalhadores e trabalhadoras. Não se volta a prestigiar o papel dos agentes coletivos na promoção de Direitos Sociais. Trata-se de uma negociação recomposta para conferir plenipotência à autonomia da vontade coletiva, viabilizando o favorecimento de interesses capitalistas ao se agregar com a fragilização dos sindicatos de trabalhadoras e trabalhadores.

Ao proporcionar uma fratura no trato Princípio da Proteção e sinalizar a possibilidade de que a negociação coletiva não se destine apenas à incorporação de novos direitos aos trabalhadores e trabalhadoras, a prevalência do negociado sobre o legislado afigura-se como importante ferramental à implementação de uma renovada lógica de acumulação de capitais que, em curto prazo e buscando inocuamente sobrevida ao cenário de crise do capital, se tentou e tenta implementar no Brasil.

Esse caráter classista poderia ser objeto de simples diagnóstico pautado na conjuntura, que não deixa esconder que a Lei n. 13.467/2017 decorre de imposição patronal

\footnotetext{
3 Jacques Wagner, então Ministro da Casa Civil do governo Dilma Rousseff, ao apagar de luzes de 2015 anuncia a necessidade de toda uma série de contrarreformas que viriam a ser encampadas no ano que o golpe se efetivou no país: "Ele [Wagner, G.S.] não deu detalhes sobre os eixos mas disse que poderão ser sobre, além da previdência, a simplificação tributária, livre negociação de questões trabalhistas entre empregador e empregadores, medidas de desburocratização", grifo nosso, in: FOLHA DE SÃO PAULO, "Governo agora acena com reforma trabalhista e previdenciária e simplificação tributária", disponível em: <http://www1.folha.uol.com.br/mercado/2015/12/1722056-equipe-economica-quer-definir-na-proximasemana-medidas-para-2016.shtml>, acessado em 24.04.2018.
} 
em um dos momentos históricos recentes de maior ofensiva burguesa frente aos interesses das trabalhadoras e trabalhadores, que, infelizmente, não encontram meios para suster seus adequados e suficientes meios de resistência.

Parte desse resgate se deu pela burguesia organizada, vocalizada por suas principais entidades representativas. Em seu canal oficial de comunicação, por exemplo, a Confederação Nacional da Indústria, poucos meses antes da aprovação da Lei n. 13.467/2017, externou sua posição acerca da temática frisando quais seriam "7 motivos para valorizar a negociação entre empresas e trabalhadores".

Percebe-se que a nota programática não deixa de evidenciar a intenção de proporcionar ganhos patronais, pressupõe indevidamente a possibilidade flexibilização de jornada - que ao avesso do alegado, é também estabelecida e protegida pela Constituição - e reclama supostos benefícios comuns impossíveis de se sustentar haja vista os próprios imperativos sistêmicos do capital, em que a indispensabilidade da exploração - dada pela apropriação dos frutos da força do trabalho tomada por subterfúgios formais e acobertada pela juridicidade - frustra qualquer perspectiva de comunhão entre as classes que antagonizam o fundamental conflito na sociedade capitalista.

No item 3 do seu rol formulado, chega a entidade patronal ao ápice do cinismo ao apontar que a "valorização" da negociação coletiva não teria finalidade outra que não otimizar, dinamicamente, os arranjos e rearranjos da funcionalização exploratória do capital.

4 “1. Concilia necessidades do empregado e empregador Por meio do diálogo, as condições de trabalho são ajustadas. Definem-se as rotinas e locais de trabalho (home office, por exemplo), benefícios, jornadas flexíveis e outras condições compatíveis com a realidade da empresa e do empregado. É a melhor forma de propiciar ganhos para ambas as partes. 2. Não elimina ou reduz direitos do trabalhador Não mexe nos direitos assegurados pela Constituição, como $13^{\circ}$ salário, FGTS, INSS, hora extra e férias. Mas permite, por exemplo, que sejam feitos ajustes na jornada de trabalho, que pode ser flexível e registrada por formas alternativas de ponto eletrônico.3. Agilidade para adaptação à realidade econômica Assim como um bom momento da economia propicia conquistas, tempos de crise exigem que empresas se adequem à realidade para enfrentar dificuldades. Ajustes rápidos, feitos de comum acordo, podem ajudar na preservação de empregos e na preparação para a retomada do crescimento. 4. Adequação a realidades regionais Empresas e trabalhadores têm necessidades que variam de acordo com seu porte, com o setor que atuam e com a região onde se encontram. Pela negociação, as partes podem discutir problemas e demandas e chegar a um consenso dentro da capacidade da empresa e que seja reciprocamente benéfico. 5. Melhora do ambiente de trabalho A negociação das rotinas e condições de trabalho fortalece o diálogo entre empresas e trabalhadores e contribui para a construção de soluções equilibradas e benéficas para os dois lados. Também pode aumentar a satisfação da equipe, ao definir rotinas flexíveis que busquem o equilíbrio entre a vida pessoal e a profissional. 6. É a boa prática internacional Em sua Convenção n ${ }^{\circ}$ 154, a Organização Internacional do Trabalho (OIT) estimula "todas as nações do mundo" a alcançar o "reconhecimento efetivo do direito de negociação coletiva", como melhor forma de equacionar os interesses de empresas e trabalhadores. O Brasil ratificou a Convenção em 1992. 7. O conflito judicial gera custo para toda a sociedade A negociação coletiva é um instrumento essencial para que empresas e trabalhadores encontrem soluções de conflito por meio do diálogo, evitando a esfera judicial, que onera o contribuinte. Para se ter ideia, há 8,4 milhões de processos na Justiça do Trabalho (2014), o equivalente a uma ação para cada seis trabalhadores formais. AGÊNCIA CNI. "7 motivos para valorizar a negociação entre empresas e trabalhadores", disponível em: <http://www.portaldaindustria.com.br/agenciacni/noticias/2016/03/7motivos-para-valorizar-a-negociacao-entre-empresas-e-trabalhadores-1/>, acessado em 23.04.2018. 
É esse, pois, o intuito maior de tal alteração legislativa. A viabilização de alterações normativas in pejus a quem trabalha, juntamente com a ruptura da rigidez das normas protetivas que regulam as relações de assalariamento e a abertura para novas e precarizantes medidas juslaborais que acabam por se manifestar como um canal ímpar de funcionalização à valorização do valor.

Tal se diz pelo fomento à reprodução ampliada da relação social do capital, proporcionando uma otimizada adequação a cada ciclo de acumulação - tanto individual quanto no que se refere a cada período histórico de afirmação capitalista -, fato que traz benefícios sobremaneira às classes proprietárias e deixa todos os encargos e ônus de tais mudanças aos trabalhadores e trabalhadoras.

Deste modo, ao abrir margens para flexibilização de condições elementares à constituição de relações de assalariamento - como é o caso de jornadas de trabalho e remuneração -, ou até mesmo situações objetivas que nenhum ajuste de vontades poderiam trazer inflexão - como são os casos dos graus de insalubridade e o reconhecimento ou não dos impactos à saúde, segurança e higiene laborais por decorrência de alterações de intervalos -, sinaliza-se um horizonte em que os marcos de exploração da força de trabalho pela minoração dos custos de contratação e ampliação da mais-valia absoluta (pela ampliação da jornada de trabalho) e relativa (pela intensificação da produtividade) venham a ser fomentados.

Daí não hesitarmos em chamar este processo de mais-valorização da negociação coletiva, haja vista seu papel fabuloso a proporcionar, dinamicamente, os rearranjos predatórios conforme a conveniência circunstancial do capitalista.

\section{Descarte da negociação coletiva ante a conveniência emergencial}

Mas a mais-valorização da negociação coletiva não esgota seus efeitos em si. Ao inaugurar um novo desenho na lida com as relações sindicais, bem como quanto ao trato do Direito do Trabalho em geral no país, as alterações advindas da Lei n. 13.467/2017, mais do que qualquer outra coisa, proporcionaram fissuras nos alicerces protetivos juslaborais, aptas a viabilizar o avanço dos interesses patronais imediatos quanto ao trato da regulamentação das relações trabalhistas. Não expressam, pois, de modo algum uma crença na concertação social por meio da negociação coletiva, mas sim o rebaixamento objetivo da proteção social, que serve de nova referência aos futures ataques classistas.

Esse fato se denota de forma evidente no curso da crise sanitária sem precedentes experimentada no curso do ano de 2020, resultante da pandemia da COVID-19. O reclamado 
isolamento social, com vistas à contenção da pandemia, trouxe evidentes impactos econômicos, que levaram ao debate público inconcebível querela, própria do binarismo que pauta a racionalidade moderna: ou se estaria a salvaguardar a economia e os empregos, ou se estaria a fomentar políticas sanitárias de maior urgência.

Neste duro cenário, uma vez mais o temário da negociação coletivo foi posto na ordem do dia. E primeiramente, com o tensionamento negativo à sua prevalência. Percebemos pela previsão do art. $2^{\circ}$, da Medida Provisória n. 927, de 22 de março de 2020, que a livre pactuação entre empregado e empregador no estabelecimento de condições que visem a preservação de seus postos de trabalho seria a saída vislumbrada pelo poder executivo para lidar com um dos mais profundos problemas econômicos potencializados pela crise sanitária. Essa livre pactuação individual pode alcançar questões como a alteração do local de trabalho, do período de gozo de férias e feriados, jornada de trabalho, entre outras condições de labor, sendo certo que a mais grave delas resulte do permissivo para suspensão dos contratos de trabalho, previsto no art. 18 do mesmo instrumento normativo. Todavia, diante da grande polêmica que resultou tal proposição, foi logo revogada, dias depois, pela Medida Provisória n. 928.

Esta perspectiva de negociação individual de maior abrangência foi retomada, em poucas semanas, como cerne de nova Medida Provisória, esta de n. 936. Referido ato normativo não só institui Benefício Emergencial de Preservação do Emprego e da Renda, como também retomou a perspectiva de que a negociação para redução de jornada e salários, ou então suspensão do contrato de trabalho, deva ser entabulada individualmente, cabendo aos sindicatos apenas ser informados destes ajustes, na forma de seu art. 11, parágrafo quarto.

Tão logo publicada, a medida foi objeto de Ação Direta de Inconstitucionalidade tombada sob o n. 6.363 - proposta pelo partido político Rede Sustentabilidade. No bojo da referida ADI, no dia 6 de abril de 2020, o seu relator Ministro Ricardo Lewandowski, deferiu em parte medida cautelar pretendida com a ação, isso para exigir que os acordos individuais não fossem apenas participados aos sindicatos representativos de categoria profissional, mas que também devessem estas entidades de classe se manifestar pela anuência ou não quanto ao pactuado, isso no prazo de 10 dias (STF,2020).

Não entrando nos meandros da situação desconfortável e, entendemos nós, completamente inapropriada a que o decidido projetou às entidades sindicais - que passaram circunstancialmente a ficar com a responsabilidade completa em chancelar medidas precarizadoras, ou assumir então os ônus políticos de dispensas ou outras consequências trabalhistas que poderiam se projetar aos trabalhadores e trabalhadoras, ainda mais em um 
contexto em que a mobilização em moldes costumeiros se coloca impraticável -, é fundamental registrar que que tal mecânica não vicejou. Em 17 de abril de 2020, o Pleno do Supremo Tribunal Federal entendeu por não referendar a liminar conferida pelo relator, sendo a tônica maior dos votos - vencidos o relator, a Ministra Rosa Weber e Ministro Edson Fachin - a da indispensabilidade de valorização da autonomia individual da vontade e a dispensabilidade, neste momento de crise, do exercício da vontade coletiva para o delineamento de práticas flexibilizadoras da legislação trabalhista.

Uma vez mais buscando a prevalência do argumento da manutenção dos empregos a todo custo - que se esgota, efetivamente, na discursividade, não revelando qualquer experiência histórica em sentido análogo nesse resultado concreto almejado -, o Supremo Tribunal Federal esgarça a fenda que fora quilhada pela Lei n. 13.467/2017, tanto no que se refere à ampliação da autonomia individual quanto coletiva das vontades. Esta última, bem verdade, aparece como um Cavalo de Tróia que traz à ordem do dia o argumento de caráter patronal, que se reveste de lustro de favorecimento obreiro, saindo de cena e abrindo alas a uma mais perversa e profunda tônica de precarização, que projeta à individualidade do trabalhador e da trabalhadora a responsabilidade de assumir os ônus pela continuidade dos préstimos laborais, o que se dá em condições profundamente impactadas pela sua subalternidade social, política e sobretudo econômica.

\section{Conclusões}

As conclusões preliminares decorrentes da pesquisa sinalizam que o discurso da "valorização da negociação coletiva" vela a natureza historicamente firmada pelo enfrentamento das trabalhadoras e trabalhadores na composição dos instrumentos negociais, tentando ressignificá-lo a partir de marcos patronais. Mostra-se pois fundamental trabalhar, no âmbito da dogmática crítica, a afirmação da insustentabilidade jurídica das alterações legais implementadas pelos arts. 611-A e seguintes da CLT, bem como a atual redação do art. 620, Consolidado, haja vista sua incompatibilidade com o art. $7^{\circ}$, caput, da CF/1988.

De mais a mais, é certo que a abertura do permissivo à negociação coletiva, percebida como uma mais-valorização da negociação coletiva, abre fissuras a uma ainda mais intensa precarização das relações laborais. No momento emergencial proporcionado pela pandemia da COVID-19, até mesmo os marcos de precarização pela negociação coletiva foram tidos por superados, assumindo a negociação individual status de suficiência para 
precarização de vínculos, viabilizando redução de jornada e remuneração, bem como a suspensão de contratos de trabalho por tal meio.

Os sindicatos, que conferiam impessoalidade e peso coletivo à negociação de condições entre tomador e vendedor da força de trabalho, são escanteados e tidos por obsoletos no trato das relações laborais. Esta obsolescência que exsurge do julgamento da ADI 6.363, cumpre dizer, é apenas discursiva, sendo certo que o sindicato é instrumento de luta e composição social próprio da modernidade, e subsiste com importante papel no arranjo - e também na superação, dependendo de seu uso político - do modo de produção capitalista.

Assim, tomando em conta que a negociação coletiva jamais pode ser entendida como telos maior da luta sindical - mas sim de mecanismo de mediação para assentar formalmente conquistas politicamente arrancadas pela classe trabalhadora -, firmamos que esta, enquanto meio tático para superação do modelo atual de organização, não pode comportar funcionalização voltada a retrocessos dos interesses sociais, econômicos e, sobretudo, político-revolucionários das trabalhadoras e trabalhadores (SEFERIAN, 2017a, p. 326), pelo que não só uma leitura voltada à inconstitucionalidade destas medidas deve ser formalmente defendida, como também sua insubsistência deve ser politicamente encampada.

\section{REFERÊNCIAS}

AGÊNCIA CNI. "7 motivos para valorizar a negociação entre empresas e trabalhadores", disponível em: http://www.portaldaindustria.com.br/agenciacni/noticias/2016/03/7-motivospara-valorizar-a-negociacao-entre-empresas-e-trabalhadores-1/, acessado em 23.04.2018.

BATISTA, Flávio Roberto. SEFERIAN, Gustavo. Financiamento sindical, direito do trabalho e crise: aproximações empíricas à funcionalidade do direito do trabalho para o capitalismo.

Direito \& Práxis, v. 11, n.4, 2020.

BOITO JÚNIOR, Armando. O sindicalismo de Estado no Brasil: uma análise crítica da estrutura sindical. São Paulo: Hucitec, 1991.

EDELMAN, Bernard. A legalização da classe operária. Trad. Marcus Orione et alii. São Paulo: Boitempo,. 2016

FOLHA DE SÃO PAULO, "Governo agora acena com reforma trabalhista e previdenciária e simplificação tributária”, em: $<$ http://www1.folha.uol.com.br/mercado/2015/12/1722056-equipe-economica-quer-definirna-proxima-semana-medidas-para-2016.shtml>, acessado em 24.04.2018. 
MARTINS FILHO, Ives Gandra. "Valorização da negociação coletiva e flexibilização das normas legais trabalhistas”. Revista Jurídica, Brasília, v. 8, n. 79, p.01-07, jun./jul., 2006. MARX, Karl. ENGELS, Friedrich. Manifesto Comunista, Trad. Álvaro Pina. São Paulo: Boitempo, 2010.

MAUAD, Marcelo José Ladeira. Cooperativas de Trabalho: sua relação com o Direito do Trabalho. São Paulo, LTr, 1999.

MEIRELLES, Davi Furtado. “O acordo coletivo especial”. Revista do Tribunal Regional do Trabalho da $2^{\text {a }}$ Região, São Paulo, SP, n. 12, p. 39-47, 2012.

SEVERO, Valdete Souto. SOUTO MAIOR, Jorge Luiz. Os 201 ataques da "reforma" aos trabalhadores. Disponível em: $<$ https://www.jorgesoutomaior.com/blog/os-201-ataques-dareforma-aos-trabalhadores>, publicado em 08.05.2017, acessado em 09.03.2018.

PMDB. "Uma ponte para o futuro", disponível em: < https://www.fundacaoulysses.org.br/wpcontent/uploads/2016/11/UMA-PONTE-PARA-O-FUTURO.pdf>, acessado em 24.04.2018. RODRIGUEZ, Américo Plá. Princípios do Direito do Trabalho. $3^{\mathrm{a}}$ ed. Trad. Wagner D. Giglio. São Paulo: LTr, 2000.

SEFERIAN, Gustavo. Direito do trabalho como barricada: sobre o papel tático da proteção jurídica do trabalhador. Tese de doutorado defendida junto à FDUSP, 2017a.

. Leitura neoliberal do Direito do Trabalho e ideologia: cenas de ontem, hoje e amanhã. In: MURADAS, Daniela (coord.). Manipulações capitalistas e o Direito do Trabalho. Belo Horizonte: RTM, $2017 b$.

. Sobre o uso da miséria historiográfica e a relevância da investigação histórica na aplicação do Direito do Trabalho. Revista Da Faculdade De Direito Da UFG, n.43, 2019.

STF. Medida cautelar na Ação Direita de Inconstitucionalidade 6.363 Distrito Federal.

Disponível em: www.stf.jus.br/arquivo/cms/noticiaNoticiaStf/anexo/ADI6363.pdf, publicado em 04.04.2020. Acessada em 20.04.2020.

Data de recebimento: 30.04 .2020

Data de aprovação: 29.09.2020 